Article

\title{
Remote Sensing Based Analysis of Recent Variations in Water Resources and Vegetation of a Semi-Arid Region
}

\author{
Shaowei Ning ${ }^{1, *}$, Hiroshi Ishidaira ${ }^{1}$, Parmeshwar Udmale ${ }^{1}$ and Yutaka Ichikawa ${ }^{2}$ \\ 1 International Research Center for River Basin Environment (ICRE), University of Yamanashi, \\ Takeda 4-3-11, Kofu, Yamanashi 400-8511, Japan; E-Mails: ishi@yamanashi.ac.jp (H.I.); \\ pd.udmale@gmail.com (P.U.) \\ 2 Department of Civil and Earth Resources Engineering, Kyoto University, C1, Kyoto-Daigaku-Katsura, \\ Nishikyo-ku, Kyoto-shi, Kyoto 615-8540, Japan; E-Mail: ichikawa@hywr.kuciv.kyoto-u.ac.jp \\ * Author to whom correspondence should be addressed; E-Mail: yantaigold@sina.com; \\ Tel.: +81-080-8860-3857.
}

Academic Editor: Yingkui Li

Received: 8 September 2015 / Accepted: 27 October 2015 / Published: 3 November 2015

\begin{abstract}
This study is designed to demonstrate use of free remote sensing data to analyze response of water resources and grassland vegetation to a climate change induced prolonged drought in a sparsely gauged semi-arid region. Water resource changes over Hulun Lake region derived from monthly Gravity Recovery and Climate Experiment (GRACE) and Tropical Rainfall Measuring Mission (TRMM) products were analyzed. The Empirical Orthogonal Functions (EOF) analysis results from both GRACE and TRMM showed decreasing trends in water storage changes and precipitation over 2002 to 2007 and increasing trends after 2007 to 2012 . Water storage and precipitation changes on the spatial and temporal scale showed a very consistent pattern. Further analysis proved that water storage changes were mainly caused by precipitation and temperature changes in this region. It is found that a large proportion of grassland vegetation recovered to its normal state after above average rainfall in the following years (2008-2012) and only a small proportion of grassland vegetation (16.5\% of the study area) is degraded and failed to recover. These degraded grassland vegetation areas are categorized as ecologically vulnerable to climate change and protective strategies should be designed to prevent its further degradation.
\end{abstract}


Keywords: water resource variations; climate change; vegetation; semi-arid region; remote sensing

\section{Introduction}

Freshwater resources are the lifeblood of our planet. It is fundamental to the biochemistry of all living organisms. The Earth's ecosystems are linked and maintained by water; it drives plant growth and provides a permanent habitat for many species, including ourselves. However, freshwater is a resource under considerable pressure. Its stored potential (surface water, ground water, soil moisture, ice, etc.) is increasingly facing challenges from climate changes as well as anthropogenic activities. That current and future climate change is expected to significantly impact freshwater systems including rivers, streams and lakes, in terms of flow and direction, timing, availability, temperature, and its inhabitants. So understanding the information about water resource change, its driving force and potential impact in the past and future is very important for water resource management and eco-environmental protection.

In recent years, the response of water resource and vegetation to the changing climate and anthropogenic effects has been discussed extensively at regional or global scales. With the rapid development of remote sensing techniques, the reliability of satellite products relevant to water resource monitoring has greatly improved. For example, changes in terrestrial water storage are measurable through satellite gravity based approximations of equivalent water thickness to a precision of $0.5 \mathrm{~cm}$ per year. [1]. Precipitation is monitored by multiple post-processing phases of currently available satellite data (i.e., Tropical Rainfall Measuring Mission (TRMM)) to a resolution of millimeter per day [2]. Water level change in rivers and lakes is derived from altimetry satellites (i.e., Jason-1/2, ENVISAT) to a sub-meter precision [3]. Hence, satellite observations have been increasingly used in such research, exploiting their potential of providing spatially continuous and temporally recurrent estimates over regional to global scales [4].

Zhang et al. [5] used monthly precipitation observations over global land areas to analyze precipitation trends in two twentieth century periods (1925-1999 and 1950-1999), and showed that anthropogenic forcing has had a detectable influence on observed changes in average precipitation within latitudinal bands, and that these changes cannot be explained by internal climate variability or natural forcing. Syed et al. [6] characterized terrestrial water storage variations using Gravity Recovery and Climate Experiment (GRACE) and Global Land Data Assimilation System (GLDAS) at global scale, the results illustrated spatial-temporal variability of water storage change over land, with implications for a better understanding of how terrestrial water storage responds to climate change and variability. Apart from global scale studies, Fensholt and Du [7,8] assessed the regional/continental precipitation trends and showed their influence on stream flow, water level, soil moisture and vegetation changes. Moiwo et al. [9] analyzed water storage dynamics in the North China Region (an important grain-production base) using GRACE, GLDAS products in conjunction with in situ hydro-climate data, the results showed a sharp water storage depletion from April 2002 through December 2009 in that area and water loss which was more a human than a natural cause had already 
negatively influenced millions of people in the region and beyond in terms of water supply crop production, eco-environmental system and social stability.

Besides that, much research also indicates that a remote sensing approach is a cost-efficient and accurate method to monitor inland water surface and water level (case of lakes and reservoirs) dynamics which are also affected directly by climate change and human activity. Dorothea et al. [10] used a Moderate Resolution Imaging Spectro-radiometer (MODIS) surface reflectance dataset and a Modified Normalized Difference Water Index $(M N D W I)$ to map the variability of Lake Manyara's water surface area over 2000-2011. Their results implied that recent fluctuations of Lake Manyara's surface water area are a direct consequence of global and regional climate fluctuations. Duan et al. [11] proposed and evaluated a method that combined operational satellite altimetry databases with satellite imagery data to estimate water volume variations in Lake Tana. Results showed that satellite altimetry products were in good agreement with in situ water levels for Lake Tana $\left(R^{2}=0.97\right)$. Estimated water volume variations derived from satellite altimetry products and LANDSAT TM/ETM+ agreed well with in situ water volume for Lake Tana, with $R^{2}$ higher than 0.95 and Root Mean Square Error (RMSE) $9.41 \%$ of corresponding mean value of in situ measurements.

With respect to vegetation, it plays a notably important role in soil conservation, atmosphere adjustment and maintenance of climatic and whole ecosystem stability because of its natural tie connecting atmosphere, water, and soil. Surface vegetation conditions are known for their sensitivity to natural changes and anthropogenic effects, thus serving as important proxies for regional eco-environmental and global climate fluctuations. Satellite based vegetation indexes such as normalized difference vegetation index $(N D V I)$ as an efficient tool are widely used to examine the dynamic of vegetation health, density and degradation due to climate changes and anthropogenic effects [12,13].

As mentioned above, satellite remote sensing has shown promising results in the estimation of water resources and vegetation. However, in this study, we focus on the analysis of a combination of available satellite data including GRACE terrestrial water storage (TWS), TRMM, MODIS/LANDSAT, satellite altimetry data (Topex/Poseidon, Jason-1/2) coupled with in situ climate data to assess the water resource variation within a sparsely gauged area - the Hulun lake region and its impact on the eco-environment to provide useful information for future water resource management and eco-environmental protection. More specifically, this study aims (1) to provide a framework for a remote sensing based integrated assessment of water resource trends; (2) to detect trends in consistently established time series (from 2002 to 2012) of terrestrial water storage change and precipitation in a spatial distributed manner and (3) to infer the probable causes of water resource variations and its impacts on vegetation in order to contribute towards sustainable eco-environmental management.

\section{Study Area}

For this study, a representative case of the Daurian Steppe Eco-region (a most intact example of Eurasian Steppe) is selected (Figure 1). It is straddled over borders of three countries, namely, China, Mongolia and Russia $\left(111^{\circ} \mathrm{E}-119^{\circ} \mathrm{E}, 47^{\circ} \mathrm{N}-50^{\circ} \mathrm{N}\right)$. The total study area is about $290,400 \mathrm{~km}^{2}$. It covers a part of an ecologically important region-The Daurian International Protected Areas (DIPA), namely, The Hulun Lake Nature Reserve grassland. The Hulun Lake Nature Reserve is a 
reserved grassland and least influenced by human activities [14,15]. This draws attention to identify the consequences of water resource changes (consecutive years of precipitation deficit and decline in TWS) on representative natural grassland-vegetation with minimum anthropogenic disturbances.

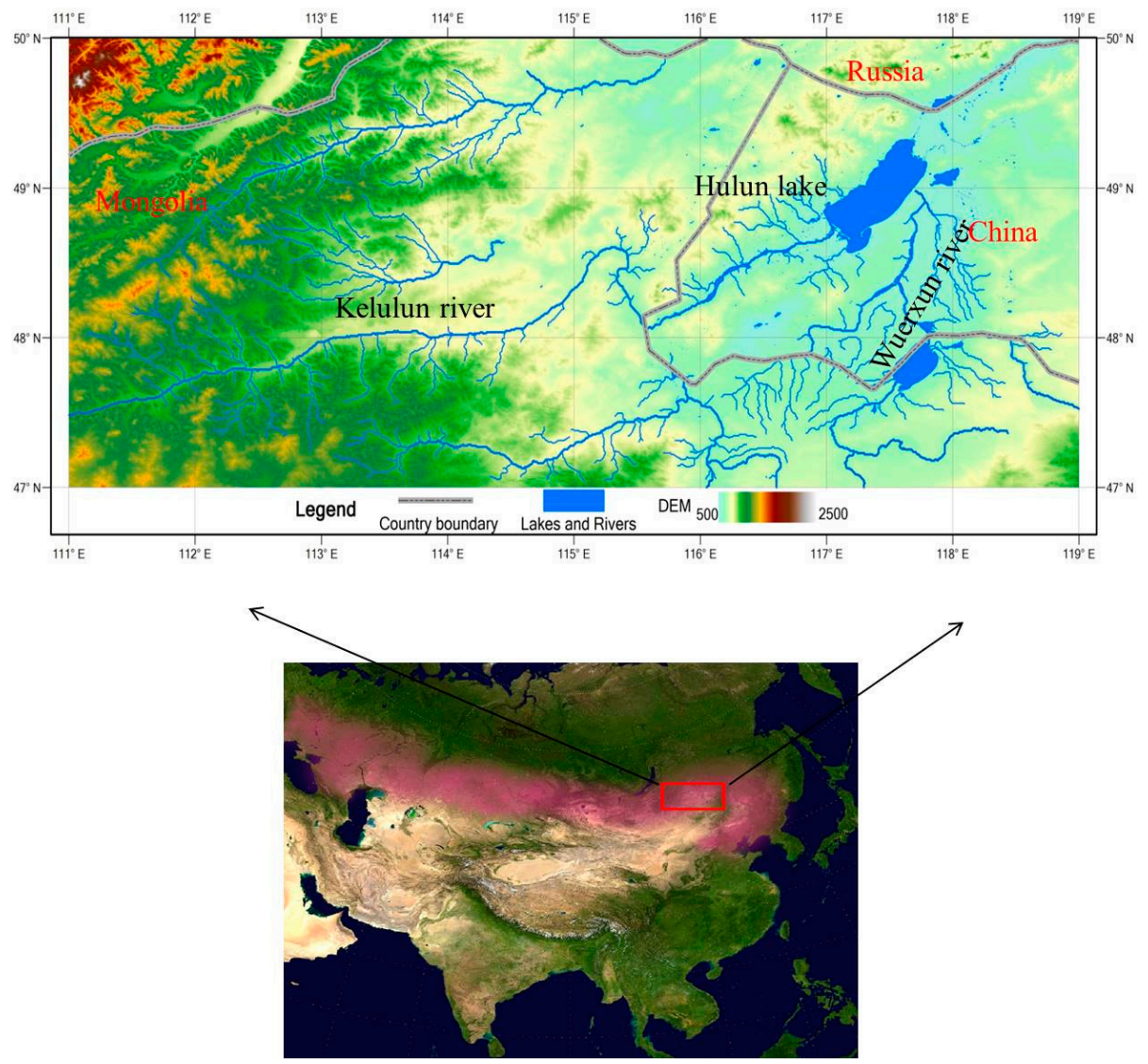

Figure 1. The geographic location and Shuttle Radar Topography Mission (SRTM)-based elevation map of the study area (red color region in the down figure shows the Eurasian Steppe zone).

The area has a mid-temperate semi-arid continental climate with the dominant mid-temperate zone characterized by drastic changes in winter and summer seasons. The average annual rainfall is about $293 \mathrm{~mm}$, mainly concentrated in unfrozen season (from May to October). The average annual temperature ranges from $-13{ }^{\circ} \mathrm{C}$ in winter to $12.3{ }^{\circ} \mathrm{C}$ in summer, the average annual evaporation is around $249 \mathrm{~mm}$, and the average annual relative humidity is $49 \%$. The semi-arid climate with the strong winds is increasing the vulnerability of this area to desertification. Figure 2 shows the vegetation cover types of the study area. About $89.9 \%$ and $7.9 \%$ of the study area is occupied by annual grass-vegetation and forest (deciduous needle leaf, deciduous broadleaf, evergreen needle leaf and annual broadleaf vegetation), respectively. The surface water bodies cover about $2.2 \%$ of study area, with a major water bodies-Hulun Lake having surface area $2307 \mathrm{~km}^{2}$ and Beier Lake with surface area $609 \mathrm{~km}^{2}$. As shown in Figure 1, there are many inland rivers in the study area, but only two rivers, Kelulun and Wuerxun river, with annual discharge about $7 \times 10^{8}$ and $5.5 \times 10^{8} \mathrm{~m}^{3}$, flow into Hulun lake which is the main drainage outlet in this area. Recently, however, the annual average discharge of these two rivers is less than $2 \times 10^{8} \mathrm{~m}^{3}$. The fluctuations in water levels of Hulun lake can be used as an indicator of wet and dry conditions in the study area. 


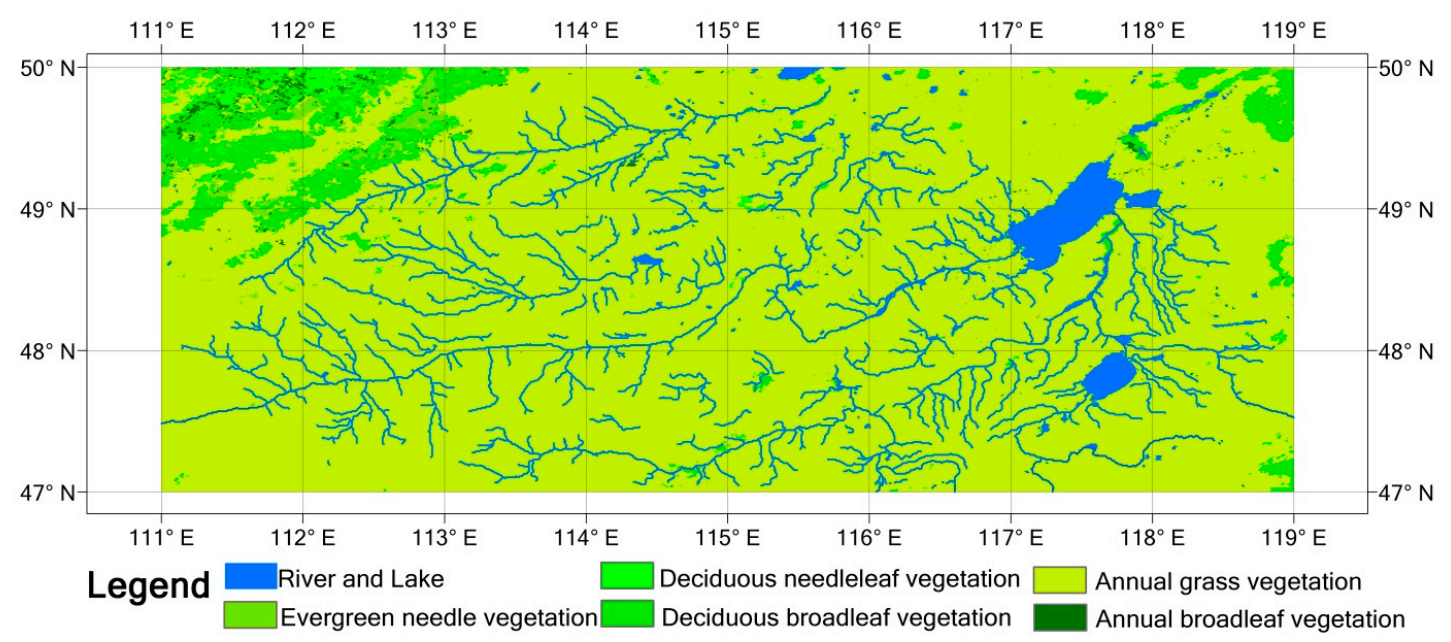

Figure 2. Vegetation map of study area.

\section{Materials}

\subsection{Precipitation Data}

The monthly precipitation for the period of 2002-2012 is obtained from Tropical Rainfall Measuring Mission (TRMM) [16]. TRMM products have been used in a number of studies of Inner Mongolia and surrounding precipitation, where they have been found to be adequate when compared with ground observations $[17,18]$. The product used in this study is referred as the TRMM and other precipitation dataset (denoted as 3B43). It is derived not only from TRMM sensors but also a number of other satellites and ground based rain gauged data. Monthly observed precipitation data (2002-2012) for five stations near the Hulun Lake are employed in this analysis to evaluate the applicability of satellite derived precipitation in study area.

\subsection{Surface Air Temperature Data}

This study uses a surface air temperature dataset namely Global Historical Climatology Network version 2 and the Climate Anomaly Monitoring System (GHCN + CAMS) which is a station observation-based global land monthly mean surface air temperature dataset at $0.5 \times 0.5$ degree resolution for the period of 1948 to the present. When compared with several existing observation-based land surface air temperature data sets, the preliminary results show that the quality of this new GHCN + CAMS land surface air temperature analysis is reasonably good and the new dataset can capture most common temporal-spatial features in the observed climatology and anomaly fields over both regional and global domains [19].

\subsection{Lake Water Level Data}

Monthly water level data for the Hulun Lake for the period of 2002-2012 is obtained from Hydroweb dataset [20]. The dataset is developed by Laboratoire d'Etudes en Oceanographie et Geode'sie Spatiale, Equipe Geodesie, Oceanographie, et Hydrologie Spatiales (LEGOS/GOHS) in Toulouse, France. It provides time series of water levels of large rivers, about 150 lakes and reservoirs, and 
wetlands around the world using the merged Topex/Poseidon, Jason-1and 2, ENVISAT and Geosat Fellow-On (GFO) data. Recent study has showed that the accuracy of water level data from Hydroweb was very high with $R^{2}$ range from 0.96 to 0.99 compared with in situ data in US, Netherlands and Ethiopia [11].

\subsection{Satellite Imagery Data}

MODIS Terra surface reflectance product (Mod09A1) [21] is employed to map and monitor spatial and temporal variations in water surface of the Hulun Lake from 2002 to 2012. Images on which snow covers the lake surface and surrounding region in winter time are not selected, because it is difficult to retrieve lake surface area in those scenes. Besides that, we also use several scenes of LANDSAT $\mathrm{TM} / \mathrm{ETM}+$ data [22] with spatial resolution of 30m to validate lake surface area derived from Mod09 A1.

\subsection{GRACE TWS Data}

TWS was derived from the latest version monthly GRACE gravity solutions (RL05) generated by the Center for Space Research at the University of Texas at Austin [23], from August 2002 through December 2012. Each solution consists of sets of spherical harmonic (Stokes) coefficients, $C_{l m}$ and $S_{l m}$, to degree 1 and order $\mathrm{m}$, both size less than or equal to 60 . We calculated these coefficients by combining GRACE data with ocean model output as Swenson et al. [24] did. TWS calculation and the post processing method used here were similar with Duan et al. [25] with two Fan filter [26] radiuses 500 and $800 \mathrm{~km}$, respectively. Finally, these coefficients were transformed into $1 \times 1$ degree gridded data that reflect vertically integrated water mass change represented by equivalent water thickness.

\subsection{NDVI Data}

NDVI dataset acquired from the Advanced Very High Resolution Radiometer (AVHRR) sensor aboard NOAA satellites processed by the Global Inventory Monitoring and Modeling Studies (GIMMS) at the National Aeronautics and Space Administration (NASA) [27]. The database ranges from July 1981 to December 2013 at a spatial resolution $8 \mathrm{~km}^{2}$. The data are composited over approximately 15 day periods with the maximum value compositing technique, which minimizes the influences of atmospheric aerosols and clouds. This study analyzes the NDVI trend for the period from 2002 to 2012.

\section{Methods}

\subsection{Water Resource Spatial-Temporal Series Analysis}

Empirical Orthogonal Functions (EOF) analysis is a widely and easily used statistical method for analyzing large multidimensional datasets. When applied to a space-time dataset, EOF analysis can be used to decompose the observed variability into a set of spatial change patterns (EOFs), which are statistically independent and spatially orthogonal to the others, and a set of times series called time coefficients (PCs) that describes the time evolution of the particular EOFs. Together, the EOFs and PCs can be combined to reconstruct the variability in the original dataset. Basically, the goal of EOF analysis is to transform an original set of variables into a substantially smaller set of uncorrelated 
variables, which can reflect most of the information of the original dataset. It also has the ability to isolate various processes mixed in observation data [28]. The EOF has recently become a popular tool in various science areas such as meteorology, geology, and geography [29]. In this study, EOF analysis is applied to study both the spatial and temporal changes of precipitation and TWS.

\subsection{Lake Water Surface Area Estimation}

Several land cover classification methods can be used for delineating water bodies from multi-temporal satellite imagery to date from conventional unsupervised methods to more advanced artificial neural networks and support vector machine classifier [12,30]. The Modified Normalized Difference Water Index (MNDWI) method proposed by $\mathrm{Xu}$ [31] has been widely applied and proved efficient to retrieve water surface. The $M N D W I$ is a band ratio index between Green (correspond to band 4 of MOD09A1 imagery) and Shortwave Infrared (SWIR, correspond to band 6 of MOD09A1 imagery) spectral bands that enhances water features. MNDWI is defined as:

$$
M N D W I=\frac{\text { Green }-S W I R}{\text { Green }+ \text { SWIR }}
$$

Following other studies [32,33], we set the threshold for $M N D W I$ to zero. $M N D W I$ values $>0$ represent water bodies and $<0$ non-water cover types. Water features have positive $M N D W I$ values because of their higher reflectance in the Green band than in the SWIR band while non-water features (soil and vegetation) have negative $M N D W I$ values due to their low reflectance in the Green band than the SWIR band. However, some parts of Hulun Lake with the average depth $5.7 \mathrm{~m}$ are very shallow, usually less than $1 \mathrm{~m}$ and many aquatic plants grow out of water surface. This makes the MNDWI values negative in some grid located inside the lake. Here, we combine the $N D V I$ value to eliminate that effect. We decide if $N D V I<0$ or $M N D W I>0$ and only one rule satisfies, then it is classified as water body. To validate the results, we estimate the water body from several scenes of LANDSAT imagery by traditional manual digitization, which is time consuming but has high accuracy.

\subsection{NDVI Variation Trend Analysis Method}

The Theil-Sen Median trend analysis, Mann-Kendall [34] are used to study the vegetation covered regions of our study area, namely, the temporal variation characteristics of the NDVI of the pixel covered region with $N D V I$ values greater or equal to 0.1 . The Theil-Sen trend analysis method can be effectively combined with the Mann-Kendall test. These are important methods for detecting the trend of long time series data, and this combination has been gradually used to analyse the long time series of vegetation reflecting the variation in trends of each pixel in a time series.

The Theil-Sen Median trend analysis is a robust trend statistical method, and it calculates the median slopes between all $n \cdot(n-1) / 2$ pair-wise combinations of the time series data. It is based on non-parametric statistics and is particularly effective for the estimation of trends in small series. The slope of Theil-Sen Median can represent the increase or decrease in the NDVI over the 11 years between 2002 and 2012 on a pixel scale. It is calculated by:

$$
T S_{N D V I}=\operatorname{median}\left(\frac{N D V I_{m}-N D V I_{n}}{m-n}\right), 2002 \leq n<m \leq 2012
$$


where, $T S_{N D V I}$ refers to the Theil-Sen median, and $N D V I_{m}, N D V I_{n}$ represent the $N D V I$ values for years of $m$ and $n$, in case of $T S_{N D V I}>0$, the NDVI shows a rising trend, otherwise, the NDVI presents a decreasing trend.

The Mann-Kendall test measures the significance of a trend. It is a non-parametric statistical test, and it has the advantage that samples do not need to follow certain distributions and is free from the interference of outliers. It has been broadly used to analyse the trends and variations at sites with hydrological and meteorological time series. Recently, this method has been applied to detection of vegetation variations over long time periods. The calculation algorithm is as follows:

It is assumed that $N D V I_{m}, \mathrm{~m}$ stands for time series from 2002 to 2012 . The statistics of $Z$ is defined as:

$$
Z= \begin{cases}\frac{S-1}{\sqrt{s(S)}} & , s>0 \\ 0 & , s=0 \\ \frac{S+1}{\sqrt{s(S)}} & , s<0\end{cases}
$$

where, $S=\sum_{n=1}^{t-1} \sum_{m=n+1}^{t} \operatorname{sgn}\left(N D V I_{n}-N D V I_{m}\right)$,

$$
\begin{gathered}
\operatorname{sgn}\left(N D V I_{n}-N D V I_{m}\right)=\left\{\begin{array}{cl}
1 & , N D V I_{n}-N D V I_{m}>0 \\
0 & , N D V I_{n}-N D V I_{m}=0 \\
-1 & , N D V I_{n}-N D V I_{m}<0
\end{array}\right. \\
s(s)=\frac{t(t-1)(2 t+5)}{18}
\end{gathered}
$$

where, $N D V I_{m}$ and $N D V I_{n}$ stands for the $N D V I$ values of the pixels $\mathrm{m}$ and $\mathrm{n}$; $\mathrm{t}$ is the length of the time series; sgn is a sign function; and the $Z$ statistic is located in the range of $(-\infty,+\infty)$. A given significance level, $|Z|>\mu_{1-\alpha / 2}$, signifies that the times series shows significant variations on the level of $\alpha$. Generally, the value of $\alpha$ is 0.05 . In this study, we choose $\alpha=0.05$, means that we measure the significance of the NDVI trend over period from 2002 to 2012 on pixel scale at a confidence level of 0.05 .

\section{Results and Discussion}

\subsection{Precipitation and Temperature Variation Analysis}

The numbers of rain-gauge stations in the study area are limited. Hence, we used TRMM monthly data to analyze precipitation trends in this study. To confirm the feasibility of TRMM data, observed precipitation from five rain gauge stations (Table 1) located in the vicinity of the study area are used. The correlation between two data sets for respective grids is observed to be in the range of $0.74-0.94$ over the period of 2002-2012 as shown in Table 1. This confirms the applicability of TRMM data for precipitation trend analysis in this study. Studies by Yatagai et al. [17] and Chen et al. [18] also validated the applicability of TRMM data in this region.

After applying EOF to TRMM data, we found three dominant EOFs and PCs in study area (as shown in Figure 3). EOF1 and PC1 represent about $65 \%$ of total variance of precipitation, which shows superposition of annual and seasonal variability. The EOF1 is found positive throughout the study area with high values in central part highlighting uniform changing pattern over study area. 
A significant decreasing trend is observed over a period of 2002-2007, however an increasing trend from 2008 to 2012 can be seen from PC1. Low negative PC1 values corresponding to summer season from 2003 to 2007 indicates five consecutive years of below average rainfall, which induced a very serious drought. Using a linear regression, we found an average precipitation decline of $23.1 \mathrm{~mm} /$ year and increase of $18.2 \mathrm{~mm} /$ year for the periods of 2002-2007 and 2008-2012, respectively. We do not interpret the second and third mode of EOF on precipitation variation (i.e., EOF2, PC2 and EOF3, PC3 here, respectively), since the temporal pattern change is not obvious, and it accounts for only $13 \%$ and $6 \%$ of variance in precipitation, respectively.

Table 1. Correlation between gauged precipitation with tropical rainfall measuring mission (TRMM) precipitation in respective grids.

\begin{tabular}{ccccc}
\hline No. & Station Name & Latitude & Longitude & $\boldsymbol{R}^{\mathbf{2}}$ \\
\hline 1 & Xinyouqi & $48.67^{\circ} \mathrm{N}$ & $116.82^{\circ} \mathrm{E}$ & 0.75 \\
2 & Xinzuoqi & $48.21^{\circ} \mathrm{N}$ & $118.27^{\circ} \mathrm{E}$ & 0.74 \\
3 & Manzhouli & $49.57^{\circ} \mathrm{N}$ & $117.43^{\circ} \mathrm{E}$ & 0.82 \\
4 & Hailaer & $49.22^{\circ} \mathrm{N}$ & $119.75^{\circ} \mathrm{E}$ & 0.92 \\
5 & Aershan & $47.17^{\circ} \mathrm{N}$ & $119.93^{\circ} \mathrm{E}$ & 0.94 \\
\hline
\end{tabular}

(a)

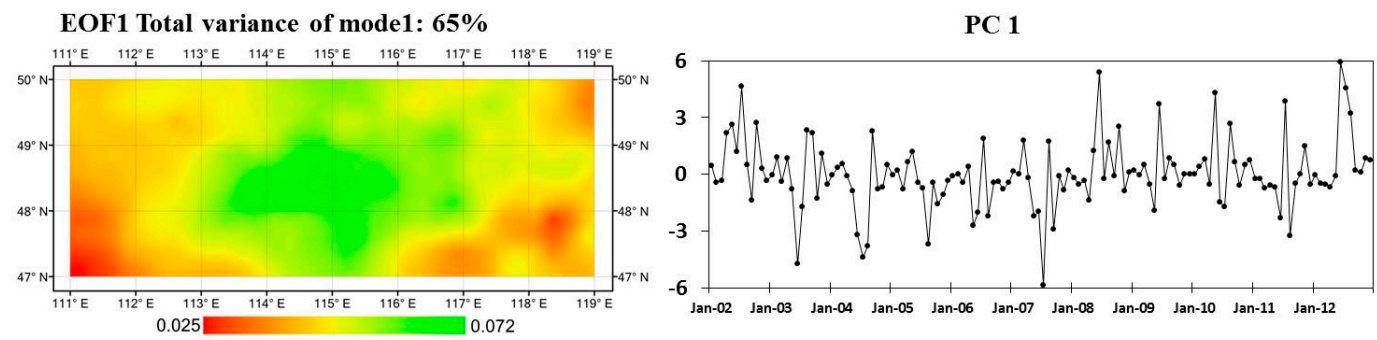

EOF2 Total variance of mode2: $13 \%$

PC 2

(b)

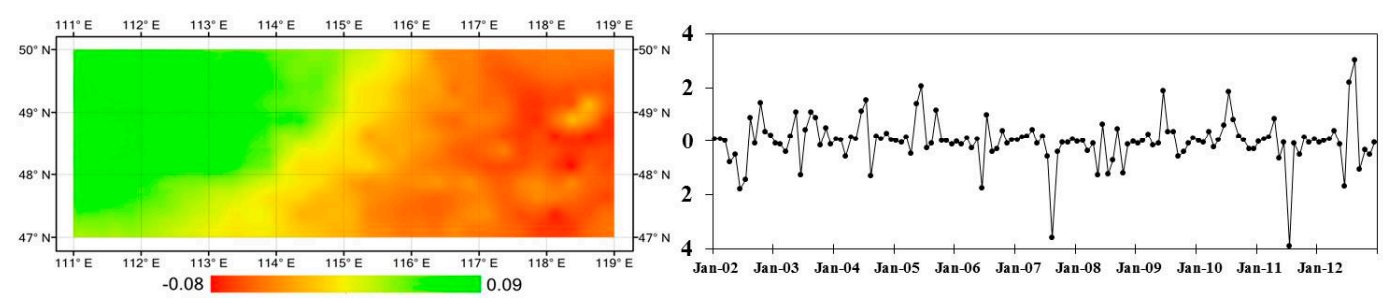

EOF3 Total variance of mode3: $6 \%$

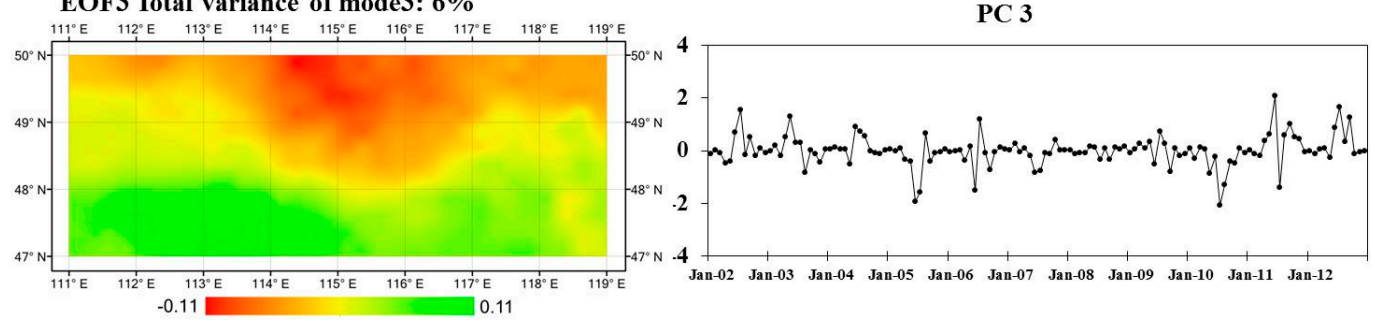

Figure 3. EOF decomposition of precipitation changes derived from TRMM satellite data over study area. EOF patterns are shown in left side and corresponding unit-less temporal patterns (PCs) in right side. (a): The first change mode of precipitation changes; (b): The second change mode of precipitation changes; (c): The third change mode of precipitation changes. 
We also analyzed the warm (May-October) and cold (November-April) season average temperature over study area as shown in Figure 4. Average temperature of warm and cold season shows opposite change pattern against precipitation. Rising temperature may have caused more evapotranspiration, then further exacerbated water storage depletion and drought.

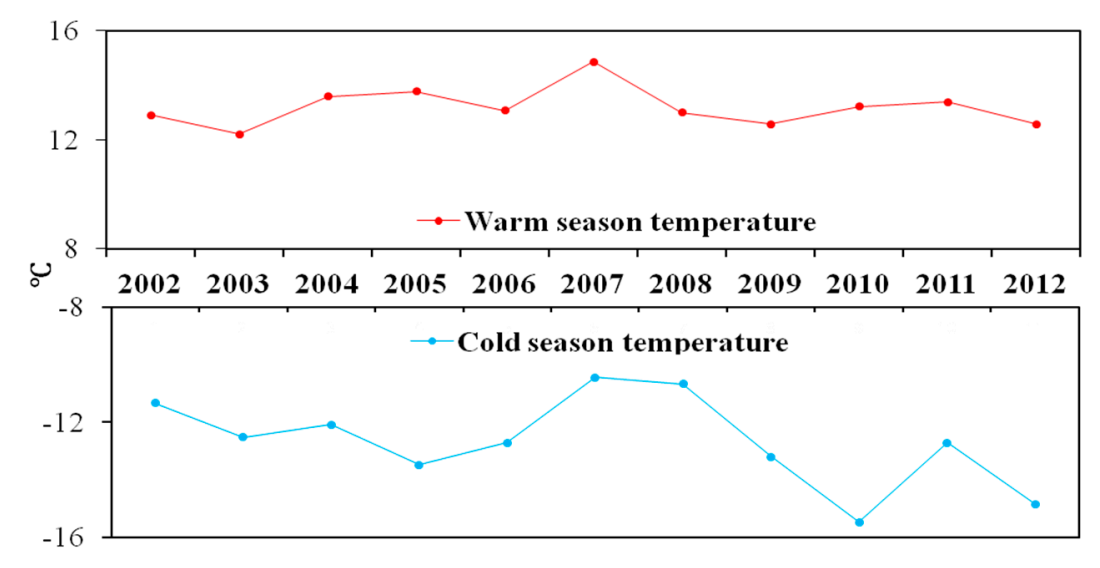

Figure 4. Temperature trend over study area from 2002 to 2012.

\subsection{Water Storage Change}

Figure 5 shows the overall EOF results of water storage variability in spatial and temporal scale over the study area. EOF analysis result provides us the general understanding of water storage change condition. EOF1 and PC1 represent $88 \%$ of total variance in water storage changes and EOF2 and PC2 represent only $10 \%$. For EOF1, all values are positive, which means all places have same change pattern with high significance in the central and north part of study area, while the corresponding PC1 shows the dominant trend. By a linear regression, we found an average water storage decline of $14.2 \mathrm{~mm} /$ year and an increase of $3 \mathrm{~mm} /$ year in the study area for the periods of 2002 to 2007 and 2008 to 2012, respectively. EOF2 delineates a spatial east-west dipole structure and PC2 shows an increasing trend in the southwest corner and decreasing trend in the east of study area over period of 2008 to 2012. Overall, the water storage first reduced sharply (2002 to 2007) and then restored slightly (2008-2012), especially in the central and north part of study area (EOF1).

EOF2 and PC2 (Figure 3) representing 13\% of total rainfall change pattern shows the similar east west dipole structure of the TWS pattern 2 (as shown in Figure 5). It is found that EOF1/2 and PC1/2 of precipitation (Figure 3) is very consistent with EOF1/2 and PC1/2 of TWS (Figure 5). This explains that the precipitation is one of the major driving factors behind water storage changes. Similar trends in precipitation and water storage changes observed over whole study area (as shown in Figure 6), which indicates a very sharp decreasing trend over the period of 2002-2007. However, for the period 2007-2012, in spite of the increasing precipitation trend, TWS did not show a significant increasing trend as that of precipitation but increased slightly. There may be two reasons for that: first, as we mentioned in the study area section, water income from the two rivers flow to this region has been lower than usual recently; second, actual evapotranspiration has increased because of above-normal vegetation development (as we will explain in Section 5.4). 
(a)

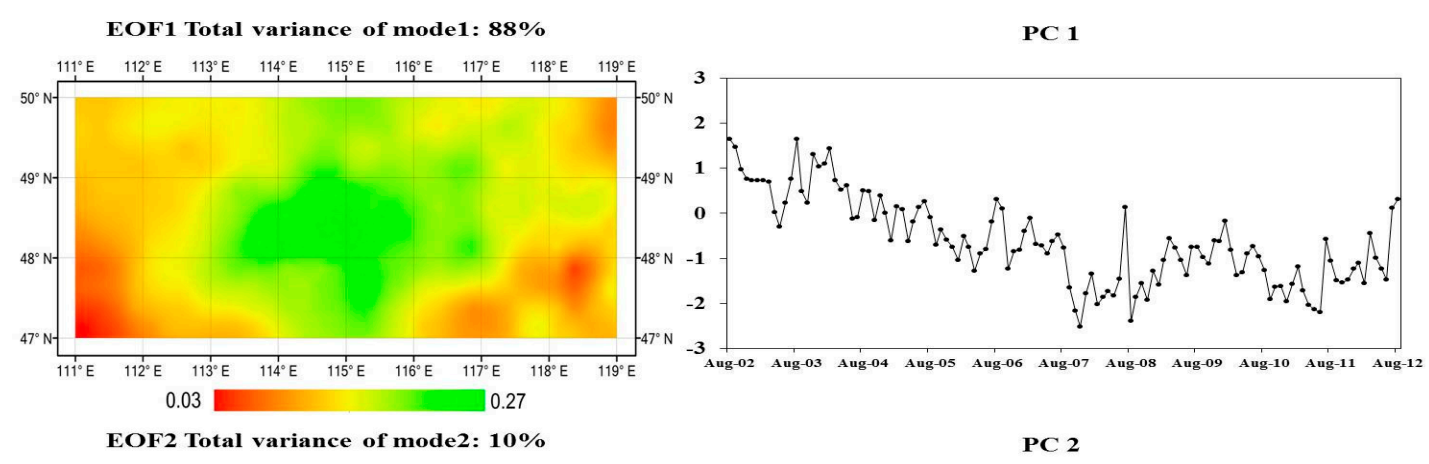

(b)

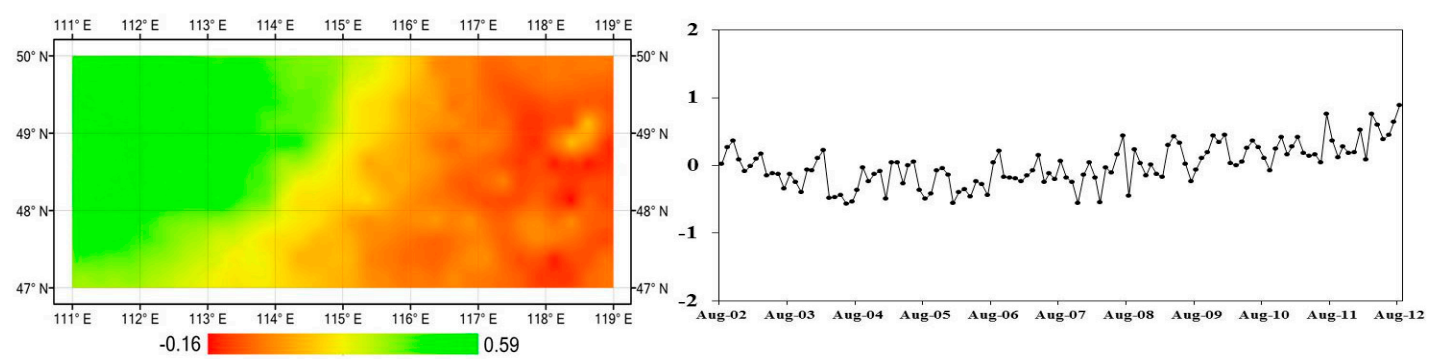

Figure 5. EOF decomposition of TWS changes over the study area. EOF patterns are shown on the left side and corresponding unit-less temporal patterns (PCs) are shown on the right side. (a): The first change mode of TWS changes; (b): The second change mode of TWS changes.

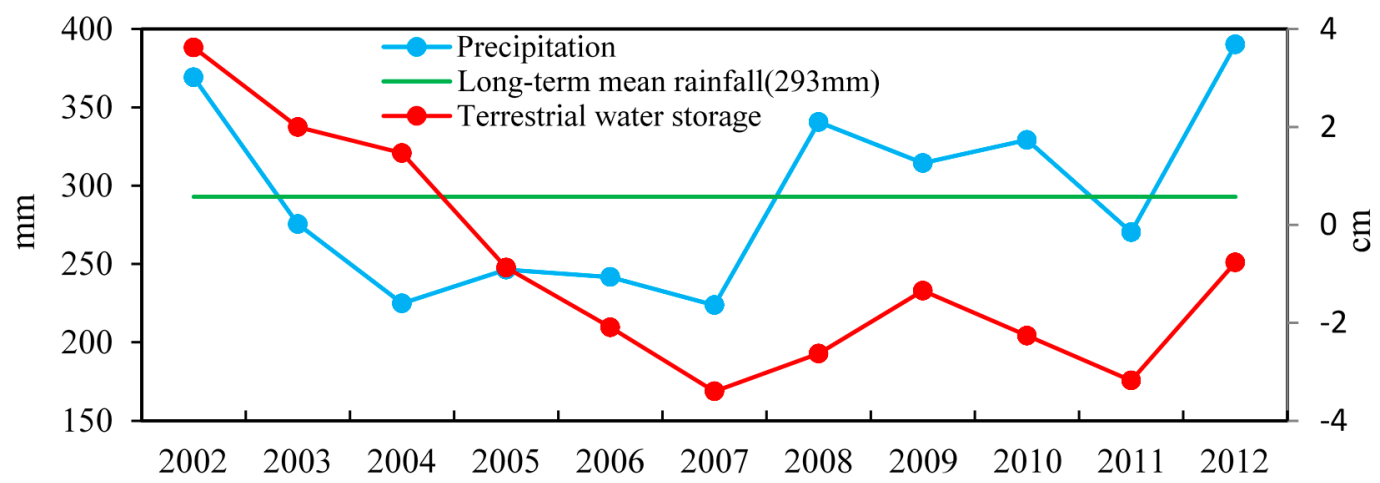

Figure 6. Annual precipitation and water storage changes series from 2002 to 2012.

\subsection{Lake Response to Water Storage Change}

As mentioned in the study area introduction, Lake Hulun drains in most parts of the study area, so its water volume change is a good indicator of water resource variation for this region. Table 2 shows the comparison between MODIS derived and LANDSAT digitalized results of lake surface area. It shows a very close relation with $R^{2}$ value as high as 0.95 and very low absolute and relative errors. It demonstrates the validity of MODIS derived lake surface area with high accuracy in unfrozen season (May-October). Figure 7 gives the lake level and lake water area time series with their correlation. Both shows rapid declination from 2002 to 2009 with about three meters of water level drop and $400 \mathrm{~km}^{2}$ of shrinkage in lake surface area, respectively, and remained stable after 2009. This temporal change pattern is not consistent with water storage and precipitation change. Although precipitation increased after 2007, lake volume still decreased till 2009 and did not show obvious rise after that. For 
this phenomenon, there may be several possible reasons. Firstly, because of drought, Lake Hulun got less inflow from the upper reaches of two main rivers (Kelulun and Wuerxun) during 2002 to 2007. According to local news, these two rivers dried up from September 2007 and did not discharge water into the lake for almost for one year [35]. Secondly, people and livestock suffering from drought, which has driven water scarcity around the lake may have withdrawn more water from it than a normal year. Finally, the most important point, a large proportion of precipitation may have been contributed to recover soil moisture deficit and depleted groundwater levels due to consecutive years of droughts. This might have delayed the river inflow and groundwater discharge to the lake. In summary, when drought attacks this region, it needs more time and water to recover to the normal state even after enough rainfall.

Table 2. Comparison of Moderate Resolution Imaging Spectro-radiometer (MODIS) and LANDSAT derived Hulun lake area.

\begin{tabular}{|c|c|c|c|c|c|}
\hline \multicolumn{2}{|c|}{ LANDSAT } & \multicolumn{2}{|c|}{ MODIS } & \multirow[b]{2}{*}{$\begin{array}{c}\text { Absolute } \\
\text { Error }\left(\mathbf{k m}^{2}\right)\end{array}$} & \multirow[b]{2}{*}{$\begin{array}{c}\text { Relative } \\
\text { Error (\%) }\end{array}$} \\
\hline Date & $\begin{array}{c}\text { Lake Surface } \\
\text { Area }\left(\mathbf{k m}^{2}\right)\end{array}$ & Date & $\begin{array}{c}\text { Lake Surface } \\
\text { Area }\left(\mathbf{k m}^{2}\right)\end{array}$ & & \\
\hline 1 July 2000 & 2306.6 & 4 July 2000 & 2290.1 & -16.4 & $-0.71 \%$ \\
\hline 6 September 2001 & 2236.4 & 7 September 2001 & 2186.3 & -50.2 & $-2.24 \%$ \\
\hline 8 August 2002 & 2154.4 & 6 August 2002 & 2221.2 & 66.7 & $3.10 \%$ \\
\hline 27 August 2003 & 2114.2 & 30 August 2003 & 2106.9 & -7.3 & $-0.35 \%$ \\
\hline 13 August 2004 & 2002.5 & 13 August 2004 & 2058.2 & 55.7 & $2.78 \%$ \\
\hline 16 August 2005 & 1977.6 & 14 August 2005 & 1948.8 & -28.7 & $-1.45 \%$ \\
\hline 26 July 2006 & 1938.6 & 29 July 2006 & 1942.9 & 4.3 & $0.22 \%$ \\
\hline 29 July 2007 & 1907.2 & 29 July 2007 & 1902.3 & -4.9 & $-0.26 \%$ \\
\hline 25 August 2008 & 1837 & 13 August 2008 & 1862.1 & 25.1 & $1.36 \%$ \\
\hline 5 October 2009 & 1791.5 & 1 October 2009 & 1772.8 & -18.7 & $-1.04 \%$ \\
\hline
\end{tabular}
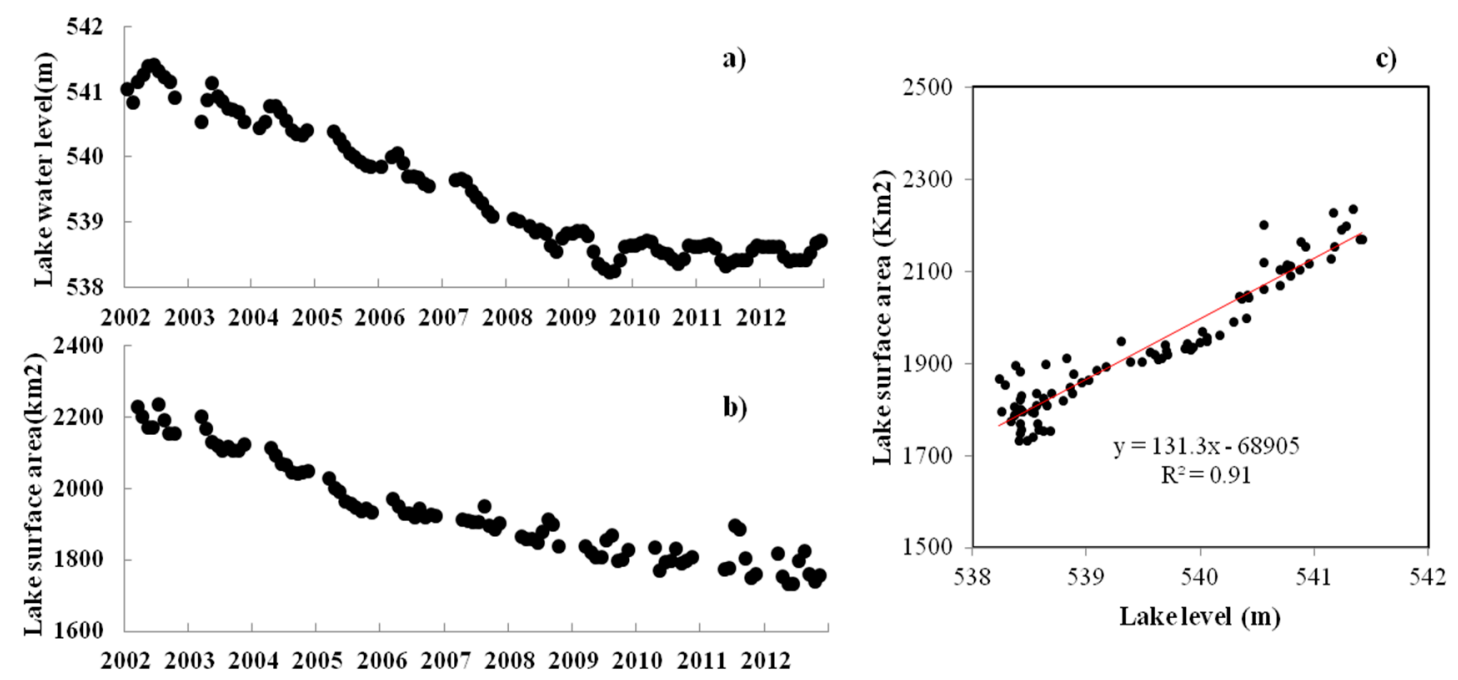

Figure 7. (a) Lake water level; (b) lake water surface area; and (c) correlation between lake water level and surface area. 


\subsection{Vegetation Response to Water Resource Change}

Average NDVI distribution over the period of 2002-2012 is shown in Figure 8a. It can be seen that the areas with high $N D V I(0.4-0.5)$ are located in northwestern part. NDVI values in central and south part of study area, and in the vicinity of lake grassland region are relatively low (0.2-0.3). The variations in trends of NDVI can be effectively captured by the Theil-Sen median trend analysis and the Mann-Kendall test to reflect the spatial distribution of vegetation responses to water resource changes. Because regions with a $T S_{N D V I}$ of 0 strictly do not exist, we made the following classifications according to the real conditions of the $T S_{N D V I}$. Regions with a $T S_{N D V I}$ from -0.0005 to 0.0005 are categorized as stable regions, regions with $T S_{N D V I}$ larger than or equal to 0.0005 are categorized improved regions and regions with $T S_{N D V I}$ less than -0.0005 are categorized as degraded areas. Moreover, significance test results of the Mann-Kendall test, at the confidence level of 0.05 , are determined as significance variations $(Z>1.96$ or $Z<-1.96)$ or insignificant variations $(-1.96 \leq Z \leq 1.96)$. Through combining the classification results of the Theil-Sen median trend analysis and the MK test, it is comparable with the data of trend variations of the NDVI. The results are summarized into five classes as shown in Table 3. It shows the regions with vegetation condition improvement, regions with stable vegetation condition, and regions with vegetation degradation, which account for $70 \%, 13.5 \%$ and $16.5 \%$, respectively.
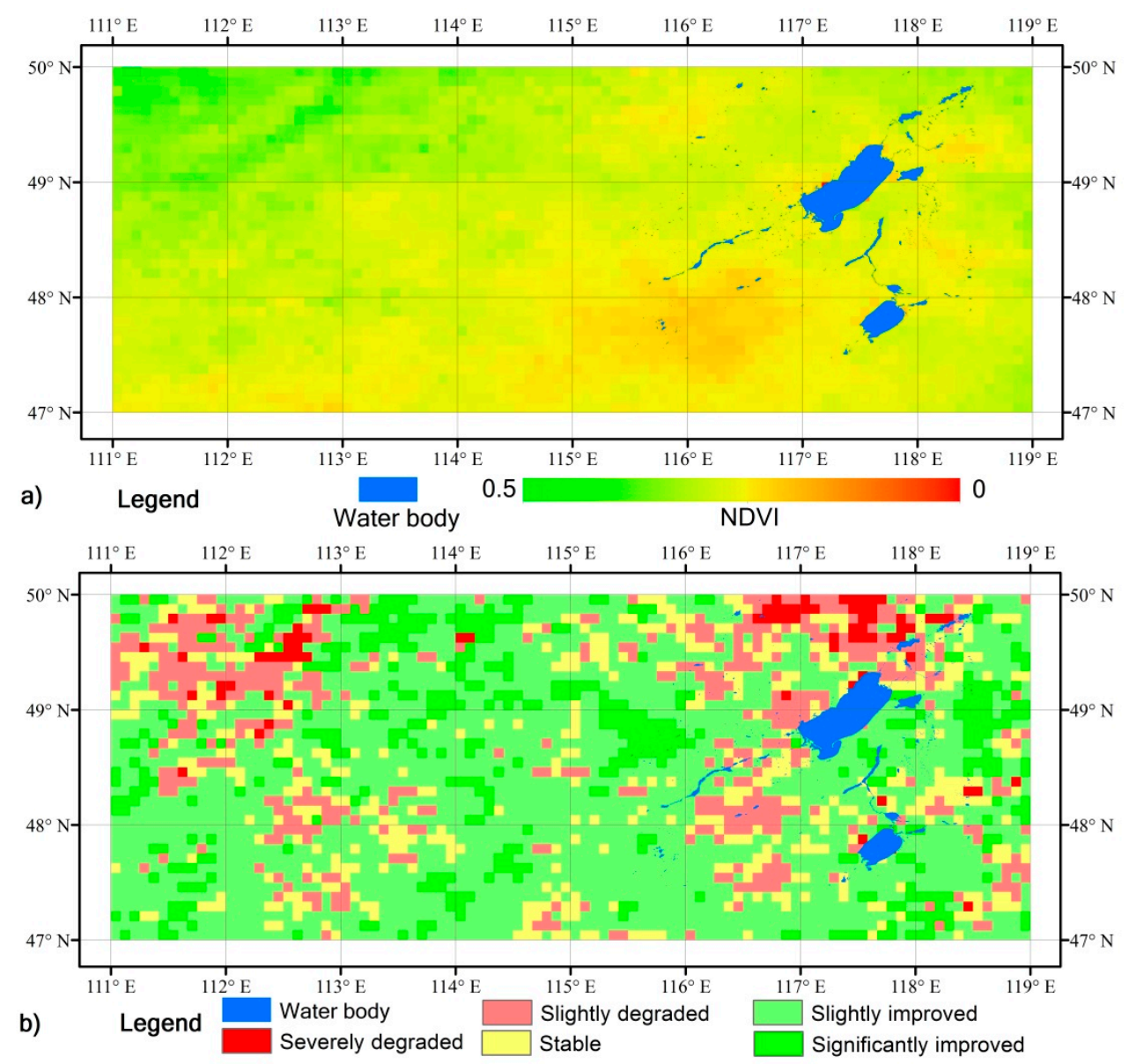

Figure 8. Spatial distribution of (a) average NDVI and (b) trends of inter-annual NDVI change over 2002 to 2012 . 
Table 3. Changing trend of normalized difference vegetation index (NDVI) in the study area.

\begin{tabular}{cccc}
\hline $\boldsymbol{T S}_{\boldsymbol{N D V I}}$ & $\boldsymbol{Z}$ & $\boldsymbol{N D V I}$ Trend & Area (\%) \\
\hline$<-0.0005$ & $<-1.96$ & Severely degraded & $2.69 \%$ \\
$<-0.0005$ & $-1.96-1.96$ & Slightly degraded & $13.80 \%$ \\
$-0.0005-0.0005$ & $-1.96-1.96$ & Stable & $13.51 \%$ \\
$\geq 0.005$ & $-1.96-1.96$ & Slightly improved & $57.35 \%$ \\
$\geq 0.005$ & $\geq 1.96$ & Improved & $12.64 \%$ \\
\hline
\end{tabular}

As shown in Figure 8b, the region with improved vegetation condition is far larger than the regions with degrading trend, and mainly scattered in the central part of the study area. This indicates resilience of grassland vegetation to droughts. The decreasing precipitation from 2002 to 2007 had not much impact on vegetation in the central part. It can be seen that the vegetation condition recovered quickly after the withdrawal of drought and the increase in precipitation in the following years. Hence, average NDVI over 2002-2012 showed an increasing trend. This shows the close relationship between vegetation conditions and precipitation as found by other researchers [36]. It is obvious to detect such vegetation conditions with a decreasing trend distributed in the northwest mountain areas and Lake Hulun surrounding areas (especially, in the northern and western part, Figure 2 shows that these are the evergreen and deciduous forest areas). Decrease in water resources had serious negative and long-term impacts on vegetation conditions. Even the precipitation increased after 2007, vegetation conditions did not recover to its normal state. We can categorize those areas as ecologically vulnerable regions, where more protective measures and effective management are needed. Possible causes about vegetation degradation in the north of Lake Hulun may have also affected by anthropogenic activities. Since it became the more important trading port between China and Russia after 2000, human activities have been more frequent than before. In addition, rapid urbanization affected vegetation conditions in this area.

\section{Conclusions}

In the present study, water resource changes over Hulun Lake region derived from monthly GRACE and TRMM products were analyzed. The EOF results from both GRACE and TRMM showed decreasing trends in water storage changes and precipitation over 2002 to 2007 and increasing trends after 2007 to 2012. Water storage and precipitation changes in spatial and temporal scale showed a very consistent pattern. Further analysis proved that water storage changes were mainly caused by precipitation and temperature changes in this region. Based on the general understanding about water resource variations, we checked the response of Hulun Lake. Results indicated that lake level and lake surface area both declined during 2002 to 2009, with about three meters of water level drop and $400 \mathrm{~km}^{2}$ shrinkage in lake surface area, respectively, and then remained stable after 2009 even though precipitation had recovered back to pre-2002 level. We can infer that water resource conditions needed more time and precipitation to recover from a long term drought in this typical semi-arid region. Furthermore, the vegetation response to water resource variations reflected that vegetation resilience to drought in most regions was high, forests were less resilient to drought than grasslands. Drought did not bring serious negative implications on vegetation growing conditions. Only $16.5 \%$ of the study area which is located in the northern and western sections of Hulun Lake and northwest mountain 
areas showed vegetation degradation. These areas that are categorized as ecological vulnerable regions need more protection and effective management in the future. Finally, this study demonstrated the feasibility of estimating water resource variation on the spatial-temporal scale and its impact on eco-environment using freely available remote sensing data in a sparsely gauged semi-arid area, which can also be adapted to other regions. Such spatiotemporally distributed analysis at the regional and basin level is particularly important considering that most of the water management and eco-environmental protection also take place at these scales.

\section{Acknowledgments}

The authors would like to express their sincere gratitude to the Ministry of Education, Culture, Sports, Science and Technology (Monbukagakusho: MEXT) and University of Yamanashi, Japan for providing financial assistance to undertake this study.

\section{Author Contributions}

Then manuscript was primarily written by Shaowei Ning, with Parmeshwar Udmale contributing to its preparation and English check. Hiroshi Ishidaira and Yutaka Ichikawa supervised the research and critically reviewed the draft.

\section{Conflicts of interest}

The authors declare no conflict of interests.

\section{References}

1. Long, D.; Scanlon, B.R.; Longuevergne, L.; Sun, A.-Y.; Fernando, D.N.; Save, H. GRACE satellites monitor large depletion in water storage in response to the 2011 drought in Texas. Geophys. Res. Lett. 2013, 40, 3395-3401.

2. Huffman, G.J.; Bolvin, D.T.; Nelkin, E.J.; Wolff, D.B.; Adler, R.F.; Gu, G.; Yang, H.; Kenneth, P.B.; Erich, F.; Stocker, E.F. The TRMM multi-satellite precipitation analysis (TMPA): Quasi-global, multiyear, combined-sensor precipitation estimates at fine scales. J. Hydrometeorol. 2007, 8, 38-55.

3. Wang, X.; Gong, P.; Zhao, Y.; Xu, Y.; Cheng, X.; Niu, Z.; Luo, Z.; Huang, H.; Sun, F.; $\mathrm{Li}, \mathrm{X}$. Water-level changes in China's large lakes determined from ICESat/GLAS data. Remote Sens. Environ. 2013, 32, 131-144.

4. Gokmen, M.; Vekerdy, Z.; Verhoef, W.; Batelaan, O. Satellite based analysis of recent trends in the ecohydrology of a semi-arid region. Hydrol. Earth Syst. Sci. Discuss. 2013, 10, 6193-6235.

5. Zhang, X.; Zwiers, F.W.; Hegerl, G.C.; Lambert, F.H.; Gillett, N.P.; Solomon, S.; Nozawa, T. Detection of human influence on twentieth-century precipitation trends. Nature 2007, 448, 461-465.

6. Syed, T.H.; Famiglietti, J.S.; Rodell, M.; Chen, J.; Wilson, C.R. Analysis of terrestrial water storage changes from GRACE and GLDAS. Water Resour. Res. 2008, 44, doi:10.1029/2006WR005779.

7. Fensholt, R.; Rasmussen, K. Analysis of trends in the Sahelian "rain-use efficiency" using GIMMS NDVI, RFE and GPCP rainfall data. Remote Sens. Environ. 2011, 115, 438-451. 
8. Du, J.; He, F.; Zhang, Z.; Shi, P. Precipitation change and human impacts on hydrologic variables in Zhengshui River Basin, China. Stoch. Environ. Res. Risk Assess. 2011, 25, 1013-1025.

9. Moiwo, J.P.; Tao, F.; Lu, W. Analysis of satellite-based and in situ hydro-climatic data depicts water storage depletion in North China Region. Hydrol. Process. 2012, 27, 1110-1020.

10. Dorothea, D.; Richard, G. Remote sensing analysis of lake dynamics in semi-arid regions: Implication for water resource management. Water 2013, 5, 698-727.

11. Duan, Z.; Bastiaanssen, W.G.M. Estimating water volume variations in lakes and reservoirs from four operational satellite altimetry databases and satellite imagery data. Remote Sens. Environ. 2013, 134, 403-416.

12. Eckert, S.; Hüsler, F.; Liniger, H.; Hodel, E. Trend analysis of MODIS NDVI time series for detecting land degradation and regeneration in Mongolia. J. Arid Environ. 2015, 113, 16-28.

13. Jiang, W.; Yuan, L.; Wang, W.; Cao, R.; Zhang, Y.; Shen, W. Spatio-temporal analysis of vegetation variation in the Yellow River Basin. Ecol. Indic. 2015, 51, 117-126.

14. Shinoda, M.; Nachinshonhor, G.U.; Nemoto, M. Impact of drought on vegetation dynamics of the Mongolian steppe: A field experiment. J. Arid Environ. 2010, 74, 63-69.

15. Da Silva, E.C.; de Albuquerque, M.B.; de Azevedo Neto, A.D.; da Silva Junior, C.D. Drought and its consequences to plants-From individual to ecosystem. In Responses of Organisms to Water Stress; InTech: Rijeka, Croatia, 2013.

16. Kummerow, C.; Barnes, W.; Kozu, T.; Shiue, J.; Simpson, J. The tropical rainfall measuring mission (TRMM) sensor package. J. Atmos. Ocean. Technol. 1998, 15, 809-817.

17. Yatagai, A.; Xie, P.; Kitoh, A. Utilization of a new gauge-based daily precipitation dataset over monsoon Asia for validation of the daily precipitation climatology simulated by the MRI/JMA 20-km-mesh AGCM. SOLA 2005, 1, 193-196.

18. Chen, Y.; Velicogna, I.; Famiglietti, J.S.; Randerson, J.T. Satellite observations of terrestrial water storage provide early warning information about drought and fire season severity in the Amazon. J. Geophys. Res. Biogeosci. 2013, 118, 495-504.

19. Fan, Y.; van den Dool, H. A global monthly land surface air temperature analysis for 1948-present. J. Geophys. Res. 2008, 113, doi:10.1029/2007JD008470.

20. LEGOS/GOHS. Available: http://www.legos.obs-mip.fr (accessed on 3 January 2013).

21. U.S. Government Computer. Available online: http://e4ft101.cr.usgs.gov/MOLT/MOD09A1 (accessed on 14 March 2015).

22. Landsat Data Access. Available online: http://landsat.usgs.gov/Landsat_Search_and_Download.php (accessed on 20 March 2015).

23. Center for Space Research. Available online: ftp://podaac.jpl.nasa.gov/allData/grace/L2/CSR/RL05/ (accessed on 12 February 2013).

24. Swenson, S.; Chambers, D.; Wahr, J. Estimating geocenter variations from a combination of GRACE and ocean model output. J. Geophys. Res. 2008, 113, doi:10.1029/2007JB005338.

25. Duan, X.J.; Guo, J.Y.; Shum, C.K.; Wal, W. On the postprocessing removal of correlated errors in GRACE temporal gravity field solutions. J. Geod. 2009, 83, 1095-1106.

26. Zhang, Z.-Z.; Chao, B.F.; Lu, Y.; Hsu, H.-T. An effective filtering for GRACE time-variable gravity: Fan filter. Geophys. Res. Lett. 2009, 36, doi:10.1029/2009GL039459. 
27. GIMMS, "ECOCAST", NASA. Available online: http://ecocast.arc.nasa.gov/data/pub/gimms/ (accessed on 19 April 2015).

28. Longuevergne, L.; Florsch, N.; Elsass, P. Extracting coherent regional information from local measurements with Karhunen-Loève transform: Case study of an alluvial aquifer (Rhine valley, France and Germany). Water Resour. Res. 2007, 43, doi:10.1029/2006WR005000.

29. Perry, M.A.; Niemann, J.D. Analysis and estimation of soil moisture at the catchment scale using EOFs. J. Hydrol. 2007, 334, 388-404.

30. Song, X.; Duan, Z.; Jiang, X. Comparison of artificial neural networks and support vector machine classifiers for land cover classification in Northern China using a SPOT-5 HRG image. Int. J. Remote Sens. 2012, 33, 3301-3320.

31. $\mathrm{Xu}, \mathrm{H}$. Modification of normalised difference water index (NDWI) to enhance open water features in remotely sensed imagery. Int. J. Remote Sens. 2006, 27, 3025-3033.

32. Deus, D.; Gloaguen, R. Remote Sensing Analysis of Lake Dynamics in Semi-Arid Regions: Implication for Water Resource Management, Lake Manyara, East African Rift, Northern Tanzania. Water 2013, 5, 698-727.

33. Cai, B.F.; Yu, R. Advance and evaluation in the long time series vegetation trends research based on remote sensing. J. Remote Sens. 2009, 13, 1170-1186.

34. Hoaglin, D.C.; Mosteller, F.; Tukey, J.W. Understanding Robust and Exploratory Data Analysis; Wiley: New York, NY, USA, 1983.

35. National Center for Agricultural Scientific Data Sharing. Available online: http:/grassland. agridata.cn/client.c?method=fgbz\&menuid=106\&id=59 (accessed on 26 May 2015).

36. Ding, M.; Zhang, Y.; Liu, L.; Zhang, W.; Wang, Z.; Bai, W. The relationship between NDVI and precipitation on the Tibetan Plateau. J. Geogr. Sci. 2007, 17, 259-268.

(C) 2015 by the authors; licensee MDPI, Basel, Switzerland. This article is an open access article distributed under the terms and conditions of the Creative Commons Attribution license (http://creativecommons.org/licenses/by/4.0/). 